\title{
Anisakis spp. burden in Trachurus trachurus
}

\author{
J. TANTANASI ${ }^{1}$, A. DIAKOU ${ }^{2}$, A. TAMVAKIS ${ }^{1}$, I. E. BATJAKAS ${ }^{1}$ \\ ${ }^{1}$ Laboratory of Ichthyology, Department of Marine Sciences, University of the Aegean 81100 Mytilene, Lesvos, \\ Greece,E-mail:jjoannious@yahoo.com,a_tamvaki@yahoo.gr,jbatzakas@mar.aegean.gr; \\ ${ }^{2}$ Laboratory of Parasitology and Parasitic Diseases, Faculty of Veterinary Medicine, Aristotle University, 54124 \\ Thessaloniki, Greece, E-mail: diakou@vet.auth.gr
}

\begin{abstract}
Summary
Anisakis is a parasite of marine mammals that uses a great number of fish species as intermediate or paratenic hosts. It is common in commercially important marine fishes and its presence is of great concern for both human health and economic reasons. Horse mackerels (Trachurus trachurus) originated from the Northern Aegean Sea were examined for the presence of Anisakis spp. larvae. The prevalence of Anisakis spp. was found $98.8 \%$. The number of parasites was significantly related to the host's length but was not related to the fish gender. The month of sampling affected the size of the fishes and consequently the number of parasites. The length of larvae was not related to the host's length. The present study resulted in the design of a prediction model for the number of existing parasites in the fish by measuring only its Fixed Length.
\end{abstract}

Keywords: Trachurus trachurus; Anisakis; Aegean Sea; prediction; host-parasite models

\section{Introduction}

The nematodes of the genus Anisakis (Nematoda, Ascaridida) are parasites of the digestive tract of the Cetaceans. They have a global distribution and use a great number of marine animals as intermediate, secondary intermediate or paratenic hosts, where the larvae occur in the body cavity, visceral organs and muscles. Terrestrial animals, including human, become incidental hosts when they consume raw or poorly cooked infected fish. Regarding Public Health, hypersensitivity and allergy due to Anisakis infection is the most common problem and it is connected to traditional dietary habits or newly imported trendy food styles (consumption of raw fish) (AAITO-IFIACI Anisakis Consortium, 2011). The prevalence (i.e. the number of hosts infected with one or more individuals of a particular parasite species, Bush et al., 1997) of larval anisakids can be very high (Chou et al., 2010). In some northern hemi- sphere fisheries the prevalence has increased in recent years, enlarging the concern for human health and having adverse financial effects (Farjallah et al., 2006; Cabrera, 2010).

There is an extensive world literature on Anisakis and anisakiosis. In late decades, in fishery and parasitology sciences the interest of many publications is focused on the prevalence of Anisakis infection, the distribution of larvae in the host and the relationship between fish's age/length and its parasitic burden (Smith, 1984; Abaunza et al., 1995; Adroher et al., 1996; Manfredi et al., 2000; Abollo et al., 2001).

Very little is known about the prevalence, the distribution or the burden of larval anisakid nematodes among the fish species found in the Aegean Sea. Horse mackerel (Trachurus trachurus) is a species commonly found in the area of Western Africa (Cape Verde Islands), Northern Sea, and Mediterranean Sea (Smith-Vaniz, 1986). It is a popular and highly commercial fish for human consumption. The aim of the present study was to investigate Anisakis spp. infection of T. trachurus from commercial fisheries of Mytilene (Lesvos Island, Greece) and to attempt the design of a model of host-parasite relationship.

\section{Materials and methods}

Initially, 68 specimens of T. trachurus were collected randomly from the Mytilene commercial fisheries, originating from the area between South-East and North costs of Lesvos Island (Fig. 1). Sampling took place from December 2006 to May 2007 with one month break (January) due to poor weather conditions. The month that each specimen was fished was recorded. After their collection, the fish were transferred to the Laboratory of Ichthyology of the Department of Marine Sciences in Mytilene and they were immediately examined. Each fish's morphometric characteristics (Total Length, Fixed Length, Head Length, Jaw- 


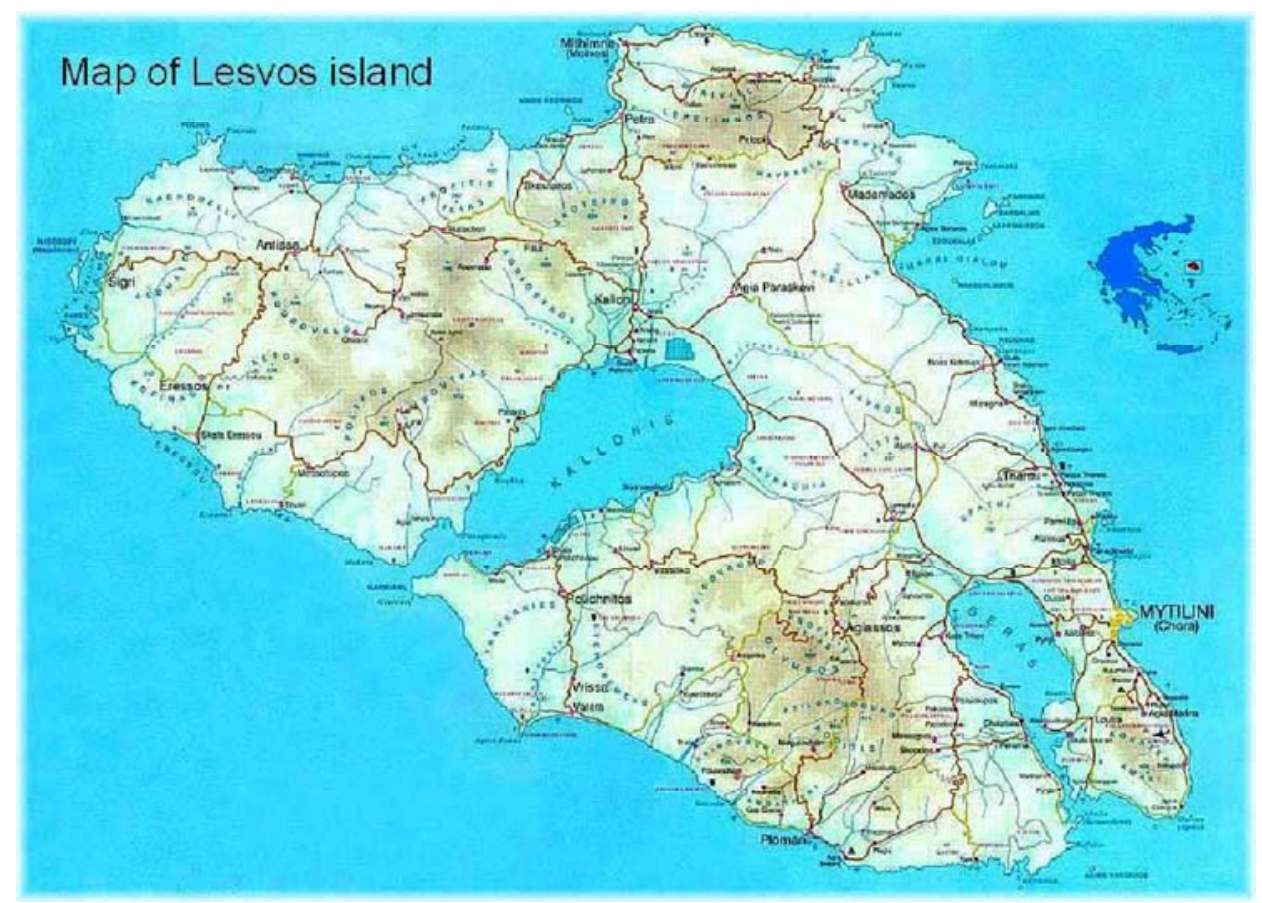

Fig. 1. Map of Lesvos Island

bone Length, Eye Diameter, Maximum Height, Minimum Height, Thickness, Total Weight, and Liver Weight) were measured (Fig. 2). Subsequently, the abdominal cavity of every fish was opened, its gender was recorded and inspection of the internal organs and muscles was performed, by direct visual examination under a stereoscope, in order to detect parasitic larvae. The number of larvae and the organ of parasitism were recorded for each fish. The larvae were collected separately for each fish and kept in an alcohol $70^{\circ}$-glycerin solution $(9: 1 \mathrm{v} / \mathrm{v})$ until they were taken to the Laboratory of Parasitology and Parasitic Diseases of the Faculty of Veterinary Medicine in Thessaloniki, where they were examined under a light microscope and identified to the Genus level, on the basis of their morphology (Hartwich, 1974; Smith, 1983; Petter \& Maillard, 1988). After the design of a prediction model of the number of existing parasites in the fish by measuring only the Fixed Length, a second sample, consisting of $16 \mathrm{~T}$. trachurus specimens was collected from the fish market of Thessalo-
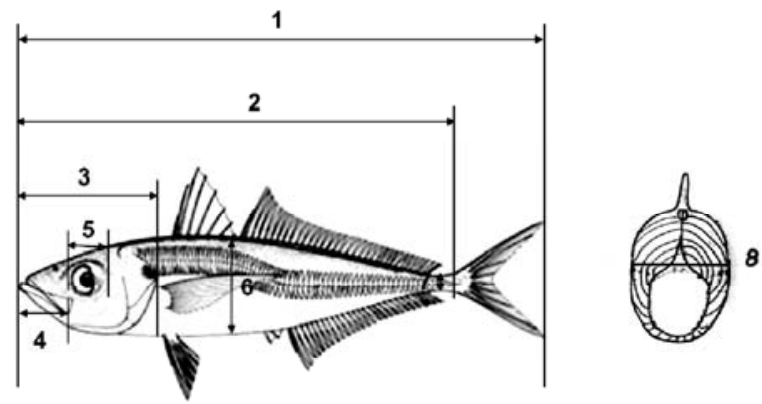

Fig. 2. Morphometric characteristics of the fish: Total Length (1), Fixed Length (2), Head Length (3), Jawbone Length (4), Eye Diameter (5), Maximum Height (6), Minimum Height (7) and Thickness (8). niki (Northern Greece) in May 2008, in order to confirm the precision of the prediction model. These fish also originated from the Northern Aegean Sea, mainly from the area near Thessaloniki. In the specimens of the second sampling the Fixed Length of the fish and the number of parasites were calculated in the same way as in the first collection.

A regression equation for each of two data sets was calculated and then two t-tests were applied among the coefficients of the lines that derive from the different sets of data in order to determine whether the slopes and the elevations of the two regression lines are significantly different or not (Zar, 1999). Levine's and ANOVA tests were applied to compare morphometric variables. The level of significance was set at $\mathrm{p} \leq 0.05$. The statistical program used for analyses of the results was SPSS 14.0.

\section{Results}

Eighty-three out of the 84 fish examined in total (first and second sampling) were found infected with Anisakis spp. third stage larvae $(98.8 \%)$. Most larvae were found on the gonads rather than on other organs (data not shown). No larvae were found in the muscles.

Sixty per cent $(60 \%)$ of the fish specimens of the initial sampling accumulated a small number of parasites (from 0 $-30 /$ per fish), whereas in the rest of them the frequency of large numbers of Anisakis spp. diminishes (Fig. 3). The mean larvae intensity, i.e. the average intensity of the larvae among the infected fish examined (Bush et al., 1997) was $120.99 \pm 39.9$ and the range $1-447$. Twenty two per cent $(22 \%)$ of the parasitized fish beard parasites that measured up to $0.2 \mathrm{~cm}$ while $88 \%$ of them beard parasites of $1.4-2.4 \mathrm{~cm}$ in length (Fig. 4). 


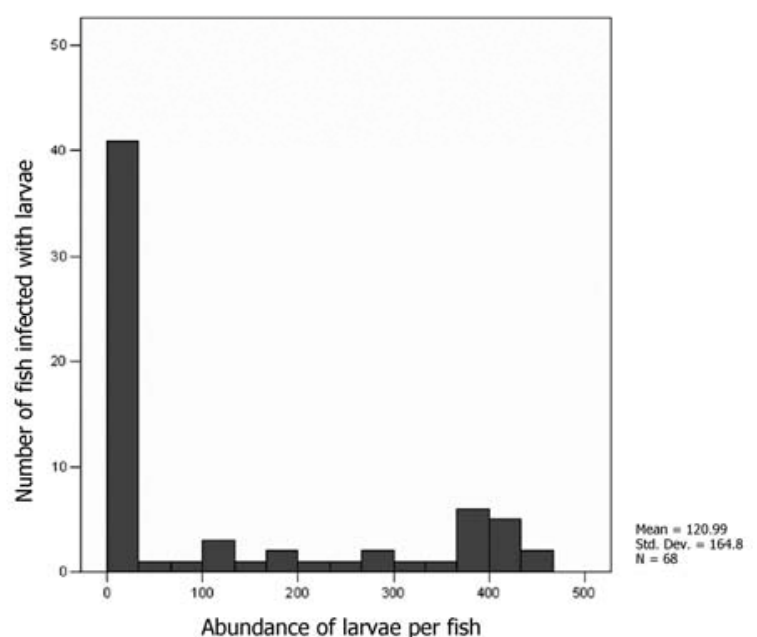

Fig. 3. Abundance of Anisakis spp. third stage larvae per fish (Trachurus trachurus)

The host's Fixed Length ranged between 13 and $33 \mathrm{~cm}$. The larval burden was related to host Fixed Length as determined by Spearman's correlation coefficient $(\mathrm{r}=$ 0.798).

In contrast, the larval length was not strongly related to the host length $(\mathrm{r}=570)$, thus the variable "parasite length" was not used for further analyses.

The fish specimens of the initial sampling were 37 females, 30 males and one immature. Levene's test for the Equality of Variances showed that the morphometric variables and the number of parasites of Anisakis spp. are independent considering the gender of the fish $(\mathrm{p}>0.05)$.

The One-way ANOVA test showed that the factor "month of sampling" affects the morphometric variables of the fish specimens as well as the number of parasites $(p=0.00$, data not shown). In more details, in February and April bigger fish and multitudinous parasites were noted, while in December, March and May smaller fish and lower parasitic burden were recorded.

Due to (1) the great significance and (2) the strong correlation between all the morphometric variables and "parasite number" it was decided to use linear regression on the data in order to produce a prediction model for the latter variable. Among all the variables that express the fish size, it was decided to use Fixed Length as an independent variable, since it is an easily measured and representing parameter of the fish's size, which presented strong linear correlation (Table 1). The regression showed a strong positive correlation between the number of parasites Anisakis spp. and the Fixed Length of horse mackerel, meaning that the prevalence of Anisakis increases with fish length (Fig. 5). Based on the data above, the prediction model resulted:

\section{$($ Log-Parasite Number $)=6.386 *(\log -$ Fixed Length $)-6.978$}

After the examination of the second sample of fish, (16 T. trachurus specimens from the fish market of Thessaloniki), two t-tests were applied among the coefficients of the lines

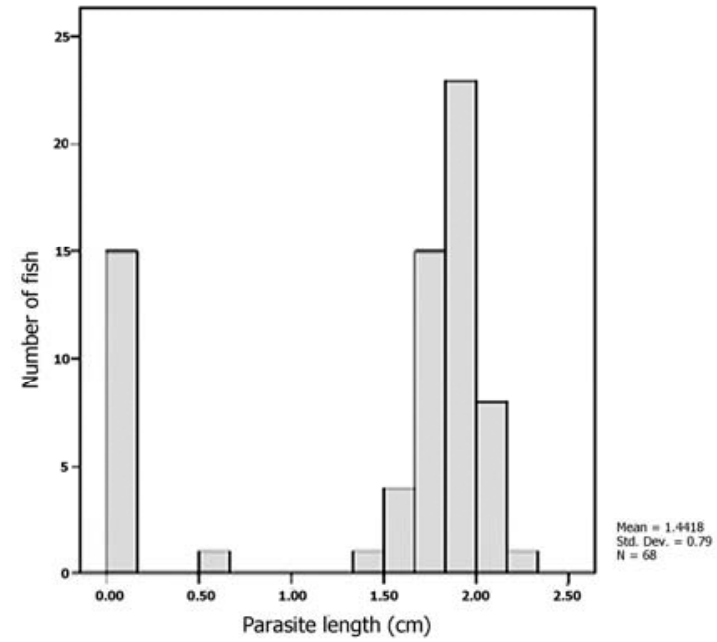

Fig. 4. Length (cm) of Anisakis spp. third stage larvae found in horse mackerel (Trachurus trachurus) specimens

that derive from the different sets of data. These tests determined that the two population regressions have neither different slopes nor different elevations (Fig. 5), both sample regressions estimate the same population regression and common regression coefficient has been configured as follows:

$($ Log-Parasite Number $)=6.399 *($ Log-Fixed Length $)-6.998$

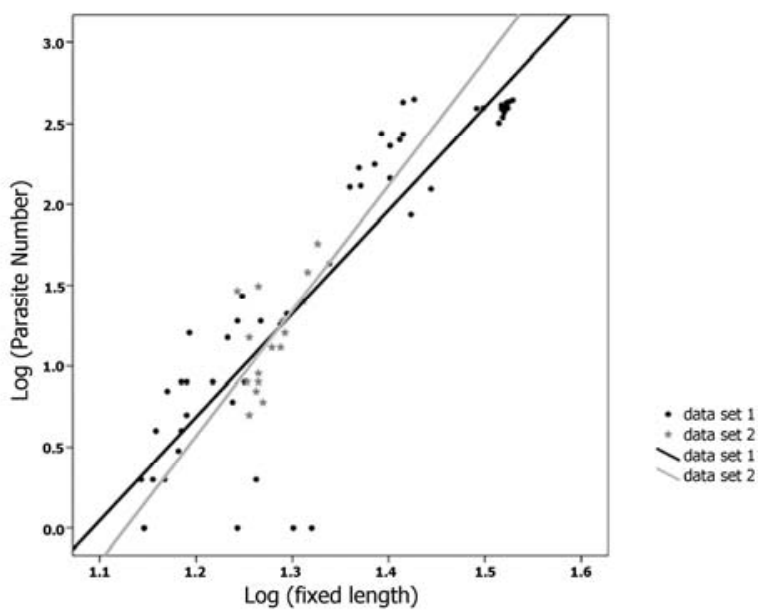

Fig. 5. Dispersion diagram of the Anisakis spp. third stage larvae number per fish (Trachurus trachurus) specimen for the first (set 1) and the second (set 2) group of examined fish

Table 1. Linear Regression of the number of Anisakis spp. third stage larvae on the Fixed Length of Trachurus trachurus

\begin{tabular}{|c|c|c|c|c|c|c|}
\hline \multirow[b]{2}{*}{ Model } & & \multicolumn{2}{|c|}{$\begin{array}{c}\text { Unstandardized } \\
\text { Coefficients }\end{array}$} & \multirow[t]{2}{*}{$\begin{array}{c}\text { Standardized } \\
\text { Coefficients }\end{array}$} & \multirow[b]{2}{*}{$\mathrm{t}$} & \multirow[b]{2}{*}{ Sig. } \\
\hline & & B & $\begin{array}{l}\text { Std. } \\
\text { Error }\end{array}$ & & & \\
\hline \multirow[t]{2}{*}{1} & (Constant) & -6.978 & 0.586 & & -11.909 & 0.000 \\
\hline & $\begin{array}{l}\text { log-Fixed } \\
\text { Length }\end{array}$ & 6.386 & 0.436 & 0.899 & 14.651 & 0.000 \\
\hline
\end{tabular}




\section{Discussion}

Horse mackerel is a pelagic fish that eats small fish and planktonic crustaceans (Muus \& Dahlström, 1974) and may therefore become infected with Anisakis spp. larvae as a secondary intermediate or paratenic host, bearing the third stage larvae (L3) of the parasite (Smith, 1983). Based on former data from Southern Europe it is confirmed that horse mackerel is one of the most commonly infected fish species by Anisakis spp. (Carvalho-Varela \& Cunha-Ferrerira, 1984; Pozzi et al., 1992; Manfredi et al., 2000). The high prevalence found in the present study (98.8\%) accentuates the concern for human health and the possible financial effects of this parasitic infection.

The parasite larvae in T. trachurus are usually located in the body cavity, viscera and muscles (Adroher et al., 1996). Reports on the distribution of Anisakis spp. larvae in some fish species showed a great variation in percentage of larvae in the viscera and the musculature and factors like the feeding habits of the host or the migratory distance for the infecting larvae within the host have been used to explain the preferences of larvae to muscles or visceral organs (Smith \& Wooten, 1975; Cattan \& Carvajal, 1984; Smith 1984; Strømnes \& Andersen, 1998; Abollo et al., 2001; Silva \& Eiras, 2003). Slow migration of the larvae from viscera to the muscle tissue or the skin after the death of the host can in some cases take place (Smith, 1984; Abollo et al., 2001). In the present study, the fish were examined only few hours after been caught and most larvae were found on the gonads rather than other organs. Strømnes and Andersen (1998) studied the presence of Anisakis spp. larvae on saithe (Pollacius virens), cod (Gadus morhua) and redfish (Sebastes marinus) and noted that the organs containing more fat beard higher number of larvae i.e. the liver in saithe and cod and the flesh in redfish.

In previous studies, the mean intensity of Anisakis presence in T. trachurus in Mediterranean waters has been reported between $15.51 \pm 22.58$ and 36.8 with the length range of the host being $23-41 \mathrm{~cm}$ and $26-42 \mathrm{~cm}$ respectively (Manfredi et al., 2000; Abollo et al., 2001). In the present study, the mean intensity was quite higher (120.99 \pm 39.9$)$. The abundance (Bush et al., 1997) of the population of Anisakis in the sea can vary greatly over a specific period of time (Smith \& Wootten, 1978) and this variation could explain the range between the levels of infection in the same fish species. Moreover, geographical differences can be observed in mean intensity of Anisakis in the horse mackerel even in a restricted geographical area (Abaunza et al., 1995). Strømnes and Andersen (2003) studied the growth of Anisakis simplex L3 larvae in three paratenic hosts (Pollachius virens, Gadus morhua and Sebastes marinus) and found a positive correlation between the length of Anisakis larvae and the age of the fish. The age-length relationship characterises growth (Abaunza et al., 1995). However, in our study the larval length was not strongly related to the host length.

The methodology used in different studies for the seasonal variation of Anisakis spp. varies. According to Smith (1983), seasonality in prevalence and intensity of Anisakis infection might not be expected because parasite eggs are shed by the final hosts throughout the year and similarly, the infection in the crustaceans is nonseasonal. However, other studies show seasonal variations of Anisakis spp. in different hosts (Strømnes \& Andersen, 2000). Previous studies showed that ascaridoid larvae accumulate in marine fish with age, predatory behaviour and increased feeding (Smith, 1984). Our results show that in December, March and May the parasitic burden in the examined fish was low whereas in February and April there was an increase but this observation is related to the correlation between the size of the fish and the number of parasites.

The larval burden was related to host length, as noted also by McGladery and Burt (1985), Abaunza et al., (1995), Adroher et al., (1996), Manfredi et al., (2000) and Cruz et al. (2007). As Abaunza et al. (1995) review, the direct relationship between infestation level and age or length in the horse mackerel is a prevalent phenomenon in many fish species. This relationship has been found to be stronger in horse mackerel than in Atlantic mackerel (Scomber scombrus) in Northern and Northern-West coasts of Spain, and it has also been noted in the flounder (Platichtys flesus), and the herring (Clupea harengus). In other species such as cod (Gadus morhua) this relationship does not seem to be so well defined. The age-length of the host is one of the main factors to be considered in analyzing infection levels of long-lived parasites, such as Anisakis (Rohde, 1993). Indeed, it has been demonstrated that anisakid larvae tend to accumulate in fish by age-length due to their predatory behaviour (Smith, 1984). Here, a prediction model that describes this relationship is proposed for the first time. It was designed based on the first sampling and was confirmed with the second sampling from a different fish market, the following year. Figure 5 shows that the sampling measurements gather around a straight line. Furthermore, the defining coefficient of regression is $\mathrm{R}^{2}=0.808$, which means that the $80.8 \%$ of the total variability is interpreted by the model, whereas the rest is attributed to error/chance. Conclusively, it was found that horse mackerel (T. trachurus) originated from the Northern Aegean Sea is heavily infected by the larvae of the nematode Anisakis spp. It has also been asserted that the parasitic population is strongly correlated to the Fixed Length of horse mackerel, meaning that the prevalence of Anisakis increases with fish length. This correlation can be expressed through a prediction model with an accuracy of $\sim 80.5 \%$. Further application and development of the model are worth studying for the calculation of Anisakis spp. in other hosts or even between the host and other parasites. Mathematical modelling of host-parasite dynamics can become a strong tool for the prevention of infections and can be very useful in a marine environment of fisheries and aquaculture.

\section{References}

AAITO-IFIACI Anisakis Consortium (2011): Anisakis hypersensitivity in Italy: prevalence and clinical features: a multicenter study. Allergy, 66: 1563 - 1569. DOI: 
10.1111/j.1398-9995.2011.02691.x

ABAunza, P., Villamor, B., PÉREZ, J. R. (1995): Infestation by larvae of Anisakis simplex (Nematoda: Ascaridata) in horse mackerel, Trachurus trachurus, and Atlantic mackerel, Scomber scombrus, in ICES Divisions VIIIb, VIIIc and Ixa (N-NW of Spain). Sci. Mar. 59(3 - 4): 223 - 233

Abollo, E., Gestal, C., Pascual, S. (2001): Anisakis infestation in marine fish and cephalopods from Galician waters: an updated perspective. Parasitol. Res., 87(6): 492 - 499. DOI: 10.1007/s004360100389

Adroher, F. J., VAlero, A., Ruiz-VAlero, J., IGlesias, L. (1996): Larval anisakids (Nematoda: Ascaridoidea) in horse mackerel $T$. trachurus from the fish market in Granada, Spain. Parasitol. Res., 82(4): 319 - 322. DOI: 10.1007/s004360050120

Bush O. A., LAfFerty K. D., Lotz J. M., Shostak A. W. (1997): Parasitology meets ecology on its own terms: Margolis et al. revisited. J. Parasitol., 83(4): 575 - 583

CABrerA, R. (2010): Anisakiasis outbreak by Anisakis simplex larvae associated to Peruvian food in Spain. Rev. Esp. Enferm. Dig., 102(10): 610 - 611. DOI: 11300108/2010/102/10/610-611

CARVAlho-VAlera, M., CunHA-Ferreira, V. (1984): Larva migrations visceral por Anisakis e outros ascarideos: helminthozoonoses potenciais por consume de peixes marinhosem Portugal. Rev. Port. Cienc. Vet., 79: 299 - 309 Cattan, P. E., Carvajal, J. (1984): A study of the migration of larval Anisakis simplex (Nematoda: Ascaridia) in the Chilean hake, Merluccius gayi (Guichenot). J. Fish Biol., 24(6): 649 - 654

Chou, Y. Y., WANG, C. S., Chen, H. G., Chen, H. Y., Chen, S. N., SHIH, H. H. (2010): Parasitism between Anisakis simplex (Nematoda: Anisakidae) third-stage larvae and the spotted mackerel Scomber australasicus with regard to the application of stock identification. Vet. Parasitol., 177(3 4): 324 - 331. DOI: 10.1016/j.vetpar.2010.12.003

Cruz, C., Barbosa C., Saraiva, A. (2007): Distribution of larval anisakids in blue whiting off Portuguese fish market. Helminthologia, 44(1): 21 - 24. DOI: 10.2478/s11687-006-0051-8

Farjallah, S., Slimane, B. B., Blel, H., Amor, N., SAID, K. (2006): Anisakid parasites of two forkbeards (Phycis blennoides and Phycis phycis) from the eastern Mediterranean coasts in Tunisia. Parasitol. Res., 100(1): $11-17$. DOI: $10.1007 / \mathrm{s} 00436-006-0227-7$

HARTWICH, G. (1974): Keys to genera of the ascaridoidea. In: Anderson, R. C., ChabAud, A. G. \& Wilmott, S. (eds) CIH Keys to the Nematode Parasites of Vertebrates, Commonwealth Agricultural Bureaux, Farnham Royal pp. 1 - 15 McGladery, S. E., BurT, D. B. (1985): Potential of parasites for use as biological indicators for migration, feeding, and spawing behavior of northwestern Atlantic herring (Clupea harengus). Can. J. Fish aquat. Sci., 42(12): 1957 - 1968. DOI: 10.1139/f85-243

Manfredi, M. T., Crosa, G., Galli, P., Ganduglia, S. (2000): Distribution of Anisakis simplex in fish caught in

RECEIVED JANUARY 19, 2011 the Ligurian Sea. Parasitol. Res., 86(7): 551 - 553. DOI: 10.1007/s004360000202

MuUs, B., DAHLSROM, P. (1974): Collins guide to the sea fishes of Britain and North-Western Europe. Collins, London, UK

Petter, A. J., Maillard, C. (1988): Larves d' Ascarides parasites de poissons en Méditerranée occidentale. Bulletin Du Museum National D' histoire Naturelle De Paris, 4: $347-369$

Pozzi, P., Ciarallo, N., Barile, N., Piermatteo, G., Vallillo, G. (1992): Presenza di larve di Anisakis nei prodotti afferent al mercato ittico di Termoli. Vet. Ital., 28: $26-30$

RoHDE, K. (1993): Ecology of Marine Parasites, 2nd ed., CAB International, Bristol, $298 \mathrm{pp}$

SILVA, M. E. R., EIRAS, J. C. (2003): Occurrence of Anisakis sp. in fishes off the Portuguese west coast and evaluation of its zoonotic potential. Bull. Eur. Assoc. Fish Pathol., 23: 13 - 17

Smith, J. W., Wootten, R. (1975): Experimental studies on the migration of Anisakis sp larvae (Nematoda: Ascaridae) into the flesh of herring, Clupea harengus. Int. J. Parasitol., 5(2): 133 - 136. DOI: 10.1016/00207519(75)90019-3

Smith, J. W., Wootten, R. (1978): Anisakis and Anisakiasis. Adv. Par., 16: $93-163$

SMITH, J. W. (1983): Anisakis simplex (Nematoda: Ascaridae): Morphology and morphometry of larvae from euphasiids and fish and a review of the life history and ecology. J. Helminthol., 57: $205-224$

SMITH, J. W. (1984): The abundance of Anisakis simplex L3 in the body-cavity and flesh of marine teleosts. Int. J. Parasitol., 14(5): 491 - 495. DOI: 10.1016/00207519(84)90030-4

SMith-VANIZ, W. F. (1986): Carangidae. In: WhiteHEAD, P. J. P., Bauchot, M. L., Hureau, J. C., Neilsen, J., TORTONESE, E. (Eds) Fishes of the North-eastern Atlantic and the Mediterranean. Volume II. Paris, UNESCO, pp. $815-844$

STRØMNES, E., ANDERSEN, K. (1998): Distribution of whaleworm (Anisakis simplex, Nematoda, Ascaridoidea) L3 larvae in three species of marine fish; saithe (Pollachius virens (L.)), cod (Gadus morhua (L.)) and redfish (Sebastes marinus (L.)) from Norwegian waters. Parasitol. Res., 84(4): 281 - 285. DOI: 10.1007/s004360050396

Strømnes, E., ANDERSEN, K. (2003): Growth of whaleworm (Anisakis simplex, Nematodes, Ascaridoidea, Anisakidae) third-stage larvae in paratenic fish hosts. Parasitol. Res., 89(5):335 - 341. DOI: 10.1007/s00436-002-0756-7

StrøMnES, E., ANDERSEN, K. (2000): "Spring rise" of whaleworm (Anisakis simplex; Nematoda, Ascaridoidea) third-stage larvae in some fish species from Norwegian waters. Parasitol. Res., 86(8): 619 - 624. DOI: 10.1007/PL00008541

ZAR, H. J. (1999): Biostatistical Analysis, 4th edition, Prentice-Hall, New Jersey

ACCEPTED NOVEMBER 16, 2011 